\title{
DESIGN FOR ADDITIVE MANUFACTURING: IS IT AN EFFECTIVE ALTERNATIVE? PART 1 - MATERIAL CHARACTERIZATION AND GEOMETRICAL OPTIMIZATION
}

\author{
FRANCO CONCLI $^{1}$, MARGHERITA MOLINARO $^{2}$ \& ELEONORA RAMPAZZO ${ }^{1}$ \\ ${ }^{1}$ Faculty of Science and Technology, Free University of Bolzano/Bozen, Italy \\ ${ }^{2}$ Polytechnic Department of Engineering and Architecture, University of Udine, Italy
}

\begin{abstract}
Additive manufacturing (AM) is becoming a more and more widespread (and trendy) approach. Its flexibility and capability to manufacture any topology has opened new possibilities: AM could lead to significant performance improvements thanks to the exploitation of lattice or reticular structures as partial replacement of the traditional solid design. The potential of this technology knows no bounds. However, in the real world, the lower performances of the materials and the high manufacturing costs significantly restrict the fields of application for which the adoption of AM results effective. In this context, the mechanical static and fatigue properties of a 17-4 PH stainless steel produced via AM were experimentally measured and compared with those of the wrought material to quantify the performance reduction. Based on these data, three components, namely a hip prosthesis, a blow plastic bottle die, and an automotive gear were selected as representative examples to show the pros and contra of AM. The three components were chosen because they belong to three quite dissimilar fields and are produced in different batch sizes. The three original designs were specifically optimized for AM by means of finite element (FE) simulations. The new solutions fulfil the strength requirements of the original parts showing at the same time reduced weights and inertias. The traditional and new designs were compared in terms of production times and costs to quantify the real benefits of AM for different applications.

Keywords: additive manufacturing, FEM, optimization.
\end{abstract}

\section{INTRODUCTION}

The main goal of this work is to investigate the effectiveness of additive manufacturing (AM) as alternative to traditional machining. To have a more complete overview, a first part of the research was focused on the characterization of an AM 17-4 PH stainless steel and the comparison of its mechanical properties with those of the wrought counterpart.

In this regard, two series of samples were manufactured via laser powder bed fusion (LPBF ISO/ASTM 52900) according to ASTM-E606 [1].

Some authors have proven that the mechanical properties of this steel manufactured via L-PBF are comparable or slightly above those of wrought counterpart [2]. This is mainly due to the rapid cooling rates that characterize the additive manufactured parts, leading to a finer micro-structure [3]. The high solidification speeds characteristic to the L-PBF process, in fact, impede the formation of the martensite phase in the as-built material leading to a metastable austenitic micro-structure [4]-[6]. Moreover, typical porosities which comes from the production process can significantly impact the mechanical properties of the material [7][10]. The voids, in fact, act as crack nucleation sites. While the characteristic porosities of AM parts could negatively affect the mechanical properties, AM shows the interesting capability to produce any kind of geometry including lattice structures and reticula, removing the geometrical constrains of the traditional manufacturing. This incredible flexibility raises another important point: lattice and reticular structures rely on thin struts that, under operation, could locally exceed the yielding leading to local plastic deformations [11]-[14]. 
To be able to consider this effect during the optimization of the structures (Design for AM), the knowledge of the cyclic behavior is fundamental. In order to have reliable data, lowcycle-fatigue (LCF) tests were performed leading to the fine-tuning of the Ramberg-Osgood (RO) model. Moreover, the tests lead to the calibration of the Basquin-Manson-Coffin (BMC) curve [15].

While the high-cycle-fatigue (HCF) failure mechanism is promoted by the cyclic elastic loading and governed by parameters such the stress concentration factor, the surface roughness and the mean stress level, in the LCF range, the failure could be related to the plastic deformations which are responsible for the trans-granular cracks initiation and propagation [16], [17].

The testing campaign relies on two series of samples. The first series was tested in the asbuild condition, while the second one was further machined to achieve a better surface finishing. This knowledge is fundamental considering that in most applications the AM lattice/reticular structures are set into operation in the as-built condition - finishing operations are not possible.

Once the material characterization was completed, the successive step of this research was focused on the geometry optimization, namely the design for AM. The optimization was performed numerically via finite element analysis (FEA). The variables for the optimization were the struts diameter and cell size, while the optimization objectives were the minimization of the mass and the deformation. The optimization was applied to three completely different components, namely a hip prosthesis, a blowing bottle mold and an automotive gear. These three components were chosen because they belong to three quite dissimilar fields and are produced in different batch sizes (these aspects will be fundamental for the economical evaluations). The three optimized solutions fulfil the strength requirements of the original parts showing at the same time reduced weights and inertias. Finally, the traditional and new designs were compared in terms of production times and costs to quantify the real benefits of introducing AM.

\section{MATERIAL CHARACTERIZATION}

Fig. 1 shows the samples used for the quasi-static (QS) tests and for the LCF tests. The geometry for the QS test consists of a smooth cylinder whose active part has a length of $35 \mathrm{~mm}$ and a nominal diameter of $5 \mathrm{~mm}$. For what concerns the LCF samples, both the asbuilt and the wrought material series have a final geometry consisting in an active length of $4.28 \mathrm{~mm}$ and a nominal diameter of $2 \mathrm{~mm}$. The geometry was designed according to the ASTM E606 standard [1].

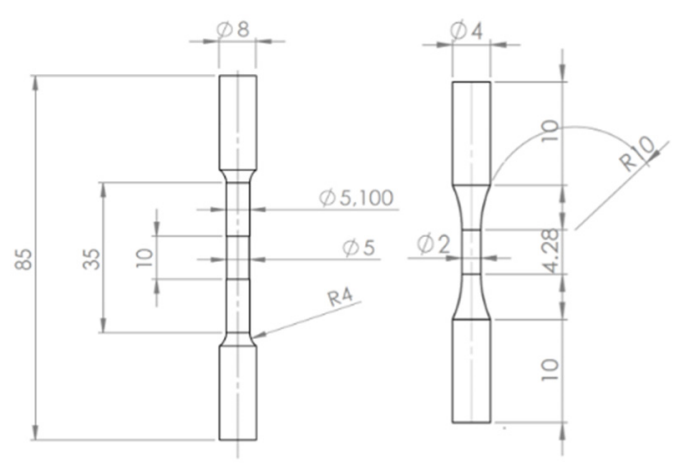

Figure 1: Specimens used for QS and LCF tests. 
Table 1 shows the chemical composition of the metal powder as provided by the producer.

Table 1: Chemical composition of powder 17-4 PH SS.

\begin{tabular}{|c|c|c|c|c|c|c|c|}
\hline $\mathrm{C}$ & $\mathrm{Si}$ & $\mathrm{Mn}$ & $\mathrm{P}$ & $\mathrm{S}$ & $\mathrm{Cr}$ & $\mathrm{Ni}$ & $\mathrm{Mo}$ \\
\hline 0.036 & 0.78 & 0.33 & 0.009 & 0.004 & 16.2 & 4.02 & 0.002 \\
\hline
\end{tabular}

\subsection{Quasi static tests}

The QS tests were performed on a STEPLab UD04 testing machine (Fig. 2) owned by the Free University of Bolzano/Bozen. The machine can apply forces up to $5 \mathrm{kN}$.

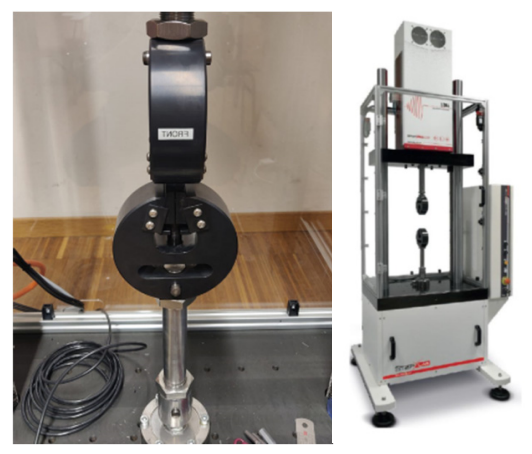

Figure 2: Tensile machine.

During the tests, the crosshead displacement was equal to $0.1 \mathrm{~mm} / \mathrm{min}$. Tests were performed at room temperature. The typical cone-cup shaped ductile fracture was observed on the specimens. The AM material shows a Yielding of $735 \mathrm{MPa}$, slightly below the one of the wrought 17-4 PH Stainless Steel (980 MPa) [18]-[21].

\subsection{Low-cycle-fatigue tests}

Strain-controlled fatigue tests were performed on the same testing machine used for the QS tests with a strain ratio $R_{\varepsilon}=-1$. The testing frequency was set to $0.1 \mathrm{~Hz}$. This value, the minimum value prescribed by the ASTM E606 [1], was kept constant during the tests. Higher speeds may affect the results promoting an increment of the temperature of the sample and a modification of the mechanical properties.

The stabilized cycles at the different stain levels were interpolated (Fig. 3) by means of the Ramberg-Osgood (RO) equation

$$
\varepsilon_{a}=\varepsilon_{a e}+\varepsilon_{a p}=\frac{\sigma_{a}}{E}+\left(\frac{\sigma_{a}}{K^{\prime}}\right)^{\frac{1}{n^{\prime}}}-
$$

where $\varepsilon_{a e}$ and $\varepsilon_{a p}$ are the elastic- and plastic-strain amplitudes, $\sigma_{a}$ the stress amplitude, $E$ the elastic module, and $K^{\prime}$ and $n^{\prime}$ are constants that depend on the material [22]. In this form $K^{\prime}$ and $n^{\prime}$ are not the same as the constants commonly seen in the Hollomon equation [23]. 


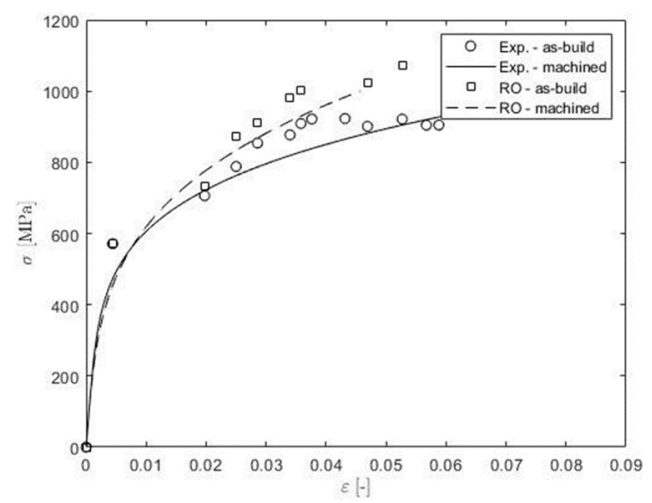

Figure 3: Ramberg-Osgood $\sigma-\varepsilon$ as-built/machined curves comparison [24], [25].

The parameters of the RO equations are reported in Table 2.

Table 2: Parameters of the Ramberg-Osgood equation.

\begin{tabular}{|l|c|c|c|}
\hline Sample & $\mathrm{K}^{\prime}[\mathrm{MPa}]$ & $\mathrm{n}^{\prime}[-]$ & $\mathrm{E}[\mathrm{MPa}]$ \\
\hline As-built & 1,705 & 0.2092 & 210,000 \\
\hline Machined & 2,392 & 0.2730 & 210,000 \\
\hline
\end{tabular}

Even after the stabilization, tests were continued up to rupture of the sample to obtain data to tune the Basquin-Coffin-Manson (BCM) fatigue equation.

$$
\varepsilon_{a}=\frac{\Delta \varepsilon}{2}=\frac{\Delta \sigma_{f}^{\prime}}{E}(2 N)^{b}+\varepsilon_{f}^{\prime}(2 N)^{c} .
$$

The BCM equation can be split in two parts: the first refers to Basquin's formulation and describes the elastic share of the deformation, while the second term, the so-called MansonCoffins' one, describes the plastic part. The first two parameters $\sigma_{f}^{\prime}$ and b are the fatigue strength coefficient and the fatigue strength exponent respectively, while $\varepsilon_{f}^{\prime}$ and c are the fatigue ductility coefficient and the fatigue ductility exponent. To calibrate these values, the ASTM 739 standard was used [26].

The calculation procedure prescribes to determine the Basquin coefficients ( $\sigma_{f}^{\prime}$ and b) starting from the yield stress $\sigma_{Y}$ and the high-cycle-fatigue limit $\sigma_{F}$ [27] with a linear interpolation. The Basquin equation can be used to separate the plastic deformation $\varepsilon_{a e}$ from the total one.

$$
\varepsilon_{a p}=\varepsilon_{a}-\varepsilon_{a e}=\varepsilon_{f}^{\prime}(2 N)^{c}
$$

To calculate $\varepsilon_{f}^{\prime}$ and c, eqn (3) can be rewritten as

$$
\log (N)=\hat{A}+\widehat{B} \log \left(\varepsilon_{a p}\right)
$$


The maximum likelihood estimators of A and B are following

$$
\begin{gathered}
\hat{A}=\bar{Y}-\hat{B} \bar{X}, \\
\widehat{B}=\frac{\sum\left(x_{i}-\bar{X}\right)\left(y_{i}-\bar{Y}\right)}{\sum\left(x_{i}-\bar{X}\right)^{2}},
\end{gathered}
$$

where $\bar{X}$ and $\bar{Y}$ are the averaged values of the dependent variable $x_{i}\left(\log \varepsilon_{a p}\right)$ and independent variable $y_{i}(\log N)$. Eqn (4) can be transformed to:

$$
\varepsilon_{a p}=10^{-\frac{\hat{A}}{\widehat{B}}}\left(\frac{1}{2}\right)^{\frac{1}{\hat{B}}}(2 N)^{\frac{1}{\widehat{B}}}
$$

Therefore, the maximum likelihood estimators of the Coffin-Manson coefficients $\varepsilon_{f}^{\prime}$ and c (eqn (3)) can be calculated as

$$
\varepsilon_{f}^{\prime}=10^{-\frac{\hat{A}}{\widehat{B}}}\left(\frac{1}{2}\right)^{\frac{1}{\hat{B}}} \text { and } c=1 / \widehat{B}
$$

The values of the calibrated BCM models are reported in Table 3.

Table 3: Parameters of the Basquin-Coffin-Manson equation.

\begin{tabular}{|l|c|c|c|c|}
\hline Sample & $\mathrm{b}$ & $\mathrm{c}$ & $\sigma_{\mathrm{f}}^{\prime}$ & $\bar{\varepsilon}_{\mathrm{f}}^{\prime}$ \\
\hline As-built & -0.0250 & -0.2365 & 390 & 0.1263 \\
\hline Machined & -0.0160 & -0.2204 & 426 & 0.1299 \\
\hline
\end{tabular}

Fig. 4 shows how the machined samples better perform with respect to the as-build ones.

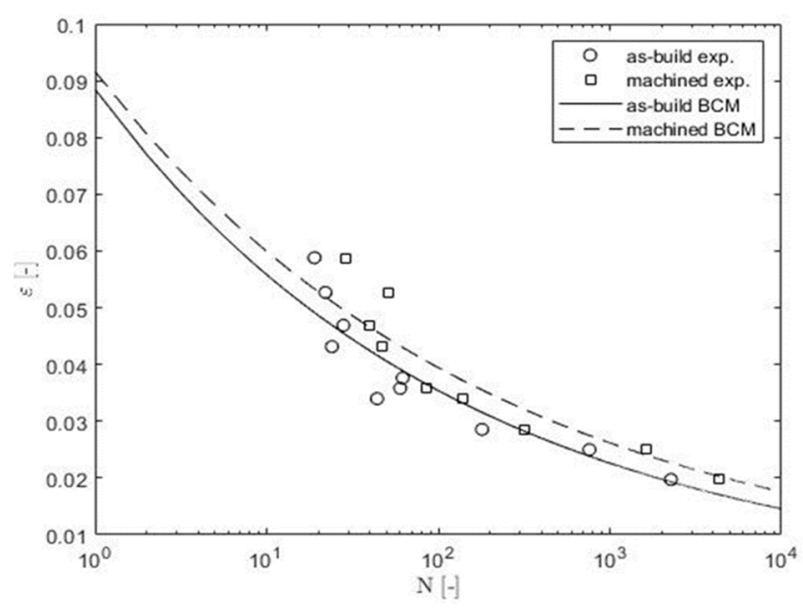

Figure 4: Resulting BMC curves. 


\section{DESIGN FOR AM}

The flexibility of AM [28] opens new scenarios in terms of optimization and re-design of existing components. In the next sections, three examples are studied. The external shape of the parts as well as the loads were considered as constraints. The optimization relies on the possibility offered by AM to substitute the solid design with reticular/lattice structures. In this way the weight and the inertias of the components could be potentially reduced with advantages also in terms of material saving and environmental impact. However, while with AM every design is feasible from a technological point of view, only through a specific optimization it is possible to maximize the benefits.

The approach used in this project foresees to optimize an elementary cell to achieve the requirements in terms of maximum stresses and deformations required by the three considered applications. After a preliminary screening based on literature, the BCC, the BCCZ and the FCC cell topologies (Fig. 5) were selected as the most appropriate for the successive steps. A parametric model of the cell was created in the open-source environment Salome-Meca/Code_Aster [29]. This Finite Element (FE) solver [30] was coupled with Dakota (Design Analysis Kit for Optimization and Terascale Applications) [31]. The mesh element size was selected after a mesh sensitivity analysis resulting in $0.15 \mathrm{~mm}$.

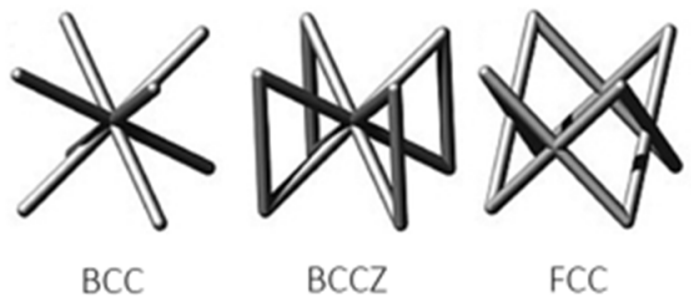

Figure 5: Cell topologies.

The optimization procedure works as follows. Starting from the unitary loads characteristics of the 3 studied systems - hip prosthesis, blowing mold and automotive gear, a first simulation was performed (for each system and cell topology combination). Based on the results in terms of maximum equivalent stress in the reticula and maximum deformation, the struts diameters and the elementary cell size were automatically modified, and the next optimization step performed. Two objective functions (mass minimization and stiffness maximization) were used. The new parameters for the successive simulations were selected according to the MOGA (Multi-objective Genetic Algorithm), which is a global optimization method that does Pareto optimization for multiple objectives. It supports general constraints and a mixture of real and discrete variables.

This approach was applied to the three different system considered. While the hip prosthesis was chosen as representative of a one-sample batch and the die mold of a small batch, the gear represents the typical series production.

\subsection{Hip prosthesis}

Since we are talking about movement, gravity and weights, the loads are dynamic and difficult to predict. At least for the standard walking, the resultant force along the entire footstep cycle lays in a direction that remains inside a small cone of action, in the superior zone of the acetabulum (Fig. 6). 

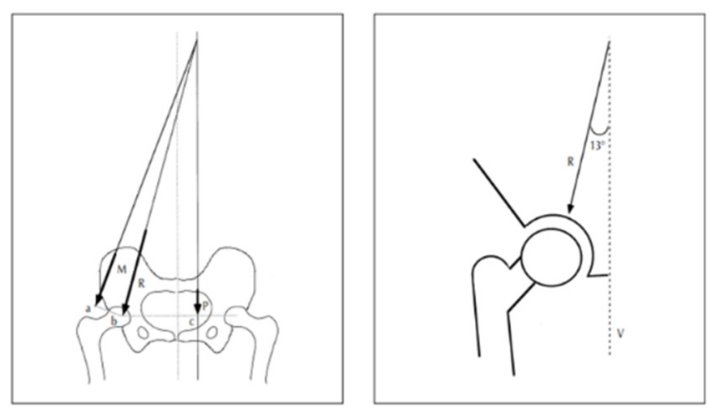

Figure 6: Loads and their angle of action on the acetabulum.

In case of monopodial loading, the force results 7-10 times the body weight of a person. Considering an average person weight of $85 \mathrm{~kg}$, the maximum load could be quantified in $6,670 \mathrm{~N}$.

The area of contact between the femur head and the acetabulum cavity is around $3,000 \mathrm{~mm}^{2}$ Therefore, the contact pressure that should be used as input for the optimization is $2.22 \mathrm{MPa}$.

\subsection{Bottle blowing mold}

The second considered object is a mold used to produce plastic bottles (Fig. 7).

The material of the bottles is Polyethylene terephthalate, better known as PET, and it is obtained from the reaction of two chemicals known as ethylene glycol (EG) and purified terephthalic acid (PAT). The production process consists of blowing pressured air into the preform letting the sides stretch until they stick to the die. The pressure can be estimated in 3.6 $\mathrm{MPa}$.
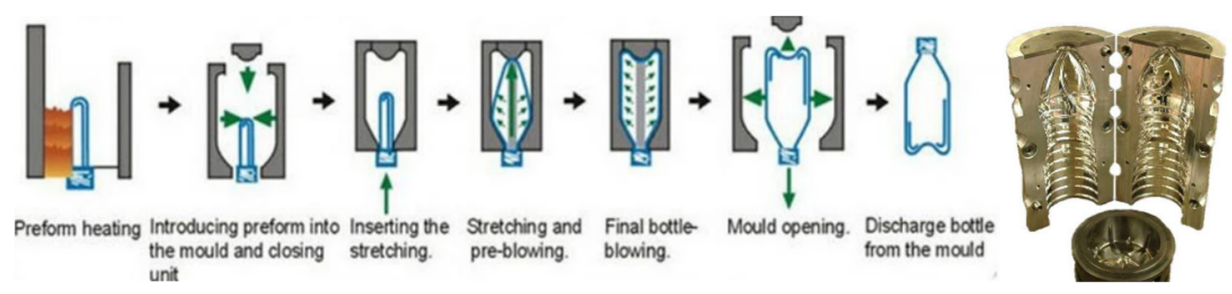

Figure 7: Stretch blow molding process step and mold geometry.

\subsection{Automotive gear}

The last mechanical component considered in this analysis is the fifth gear on the primary shaft of a Fiat Grande Punto $1200 \mathrm{cc}$ gearbox. The choice was meant to include in the analysis a mass production component. For the maximum torque $(377 \mathrm{Nm})$, the shear stress in the gear rim results equal to about $7 \mathrm{MPa}$.

All the above-mentioned levels of stress are significantly below the fatigue limit of any commercial steel and far below these of the 17-4 PH SS. This confirms that all the three considered components could be redesigned and lightened. 


\section{RESULTS OF THE OPTIMIZATION}

\subsection{Hip prosthesis}

The optimization of the three cell topologies for the hip prosthesis leads to the results shown in Table 4.

Table 4: Optimized parameters for hip prosthesis.

\begin{tabular}{|l|c|c|}
\hline Cell topology & Strut radius [mm] & Cell size [mm] \\
\hline BCC & 0.90 & 3.0 \\
\hline BCCZ & 0.97 & 3.8 \\
\hline FCC & 0.87 & 3.0 \\
\hline
\end{tabular}
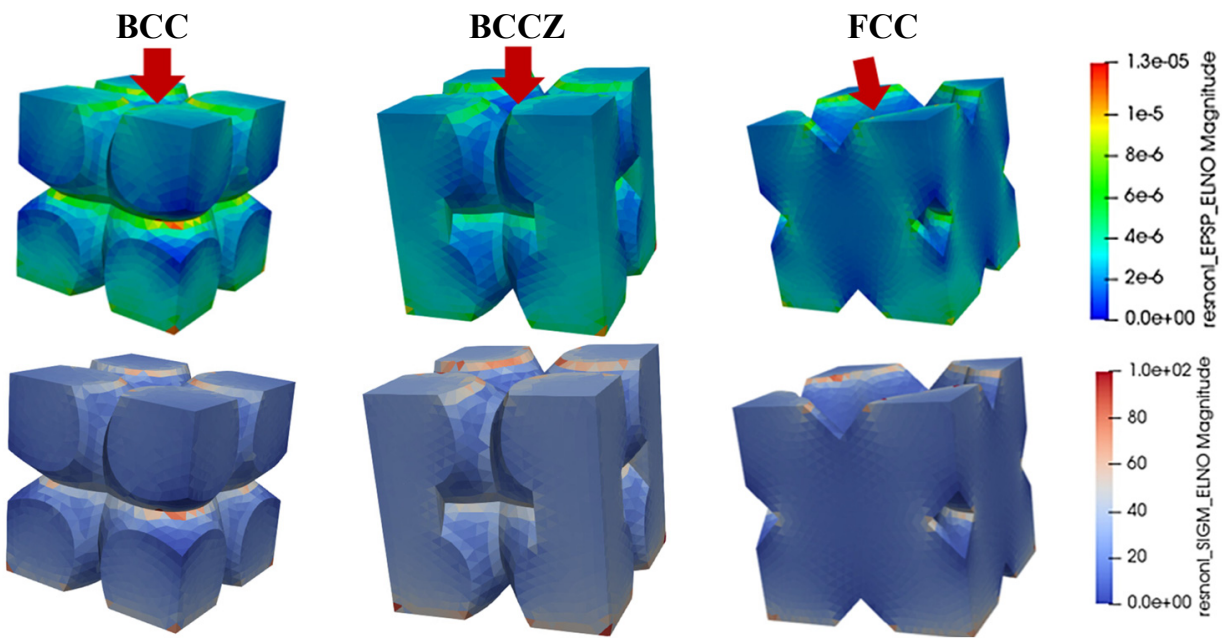

Figure 8: Optimized cells: strain and stress fields of hip prosthesis.

\subsection{Bottle blowing mold}

The optimization of the three cell topologies for the die mold leads to the results shown in Table 5.

Table 5: Optimized parameters for bottle blowing mold.

\begin{tabular}{|l|c|c|}
\hline Cell topology & Strut radius [mm] & Cell size [mm] \\
\hline BCC & 0.99 & 3.3 \\
\hline BCCZ & 0.88 & 3.0 \\
\hline FCC & 0.87 & 3.0 \\
\hline
\end{tabular}



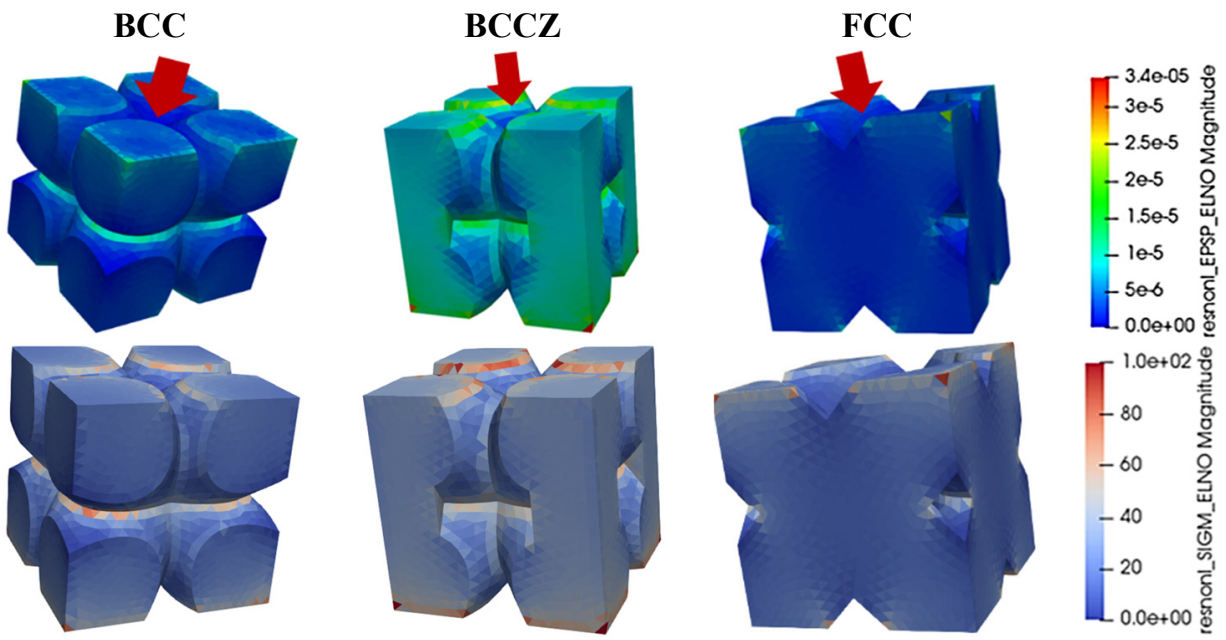

Figure 9: Optimized cells: strain and stress fields of bottle blowing mold.

\subsection{Automotive gear}

The optimization of the three cell topologies for the automotive gear leads to the results shown in Table 6.

Table 6: Optimized parameters for automotive gear.

\begin{tabular}{|l|c|c|}
\hline Cell topology & Strut radius [mm] & Cell size [mm] \\
\hline BCC & 0.90 & 3.3 \\
\hline BCCZ & 0.88 & 3.2 \\
\hline FCC & 0.80 & 3.0 \\
\hline
\end{tabular}
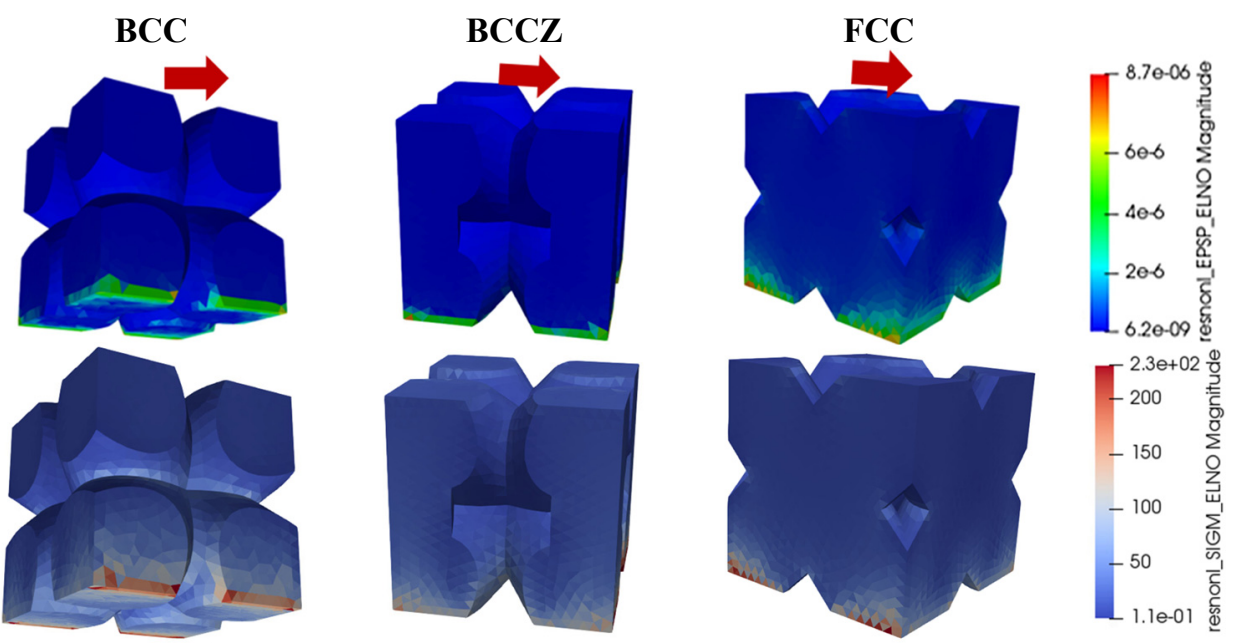

Figure 10: Optimized cells: strain and stress fields of automotive gear. 


\section{DISCUSSIONS AND CONCLUSIONS}

The first step needed to perform this activity was to characterize the AM material to base the optimization on reliable data.

Three components belonging to three quite dissimilar fields and produced in different batch sizes were considered. Their solid design was replaced by optimized lattice structure, ensuring the same reliability and maximum deformation combined with a significantly reduced weight and inertia. Three reticular cell topologies were selected, BCC, BCCZ and FCC. Their strut diameters and cell size were optimized based on FEM simulations combined with a Multi-objective Genetic Algorithm. In the second part of this paper, based on the results of this study, an economical evaluation of the effectiveness and convenience of AM will be made.

\section{REFERENCES}

[1] ASTM, Standard test method for strain-controlled fatigue testing. E606/E606M-12, vol. 96, no. 2004, pp. 1-16, 2004.

[2] Cheruvathur, S., Lass, E.A. \& Campbell, C.E., Additive manufacturing of 17-4 PH stainless steel: Post-processing heat treatment to achieve uniform reproducible microstructure. JOM, 2016.

[3] S. Steel A. 17-4 TM Precipitation ATI Technical Data Sheet and H. Alloy, Stainless Steel AL 17-4TM Precipitation Hardening Alloy. Allegheny Technologies, 2006.

[4] Hsiao, C.N., Chiou, C.S. \& Yang, J.R., Aging reactions in a 17-4 PH stainless steel. Mater. Chem. Phys., 74(2), pp. 134-142, 2002.

[5] Rafi, H.K., Pal, D., Patil, N., Starr, T.L. \& Stucker, B.E., Microstructure and mechanical behavior of 17-4 precipitation hardenable steel processed by selective laser melting. J. Mater. Eng. Perform., 23(12), pp. 4421-4428, 2014.

[6] Viswanathan, U.K., Banerjee, S. \& Krishnan, R., Effects of aging on the microstructure of 17-4 PH stainless steel. Mater. Sci. Eng. C, 104, pp. 181-189, 1988.

[7] Yadollahi, A., Shamsaei, N., Thompson, S.M., Elwany, A. \& Bian, L., Mechanical and microstructural properties of selective laser melted 17-4 ph stainless steel. ASME International Mechanical Engineering Congress and Exposition, Proceedings (IMECE), vol. 2A-2015, 2015.

[8] Wu, J.H. \& Lin, C.K., Influence of high temperature exposure on the mechanical behavior and microstructure of 17-4 PH stainless steel. J. Mater. Sci., 38(5), pp. 965971, 2003.

[9] Mirzadeh, H. \& Najafizadeh, A., Aging kinetics of 17-4 PH stainless steel. Mater. Chem. Phys., 116(1), pp. 119-124, 2009.

[10] Luecke, W.E. \& Slotwinski, J.A., Mechanical properties of austenitic stainless steel made by additive manufacturing. J. Res. Natl. Inst. Stand. Technol., 119, pp. 398-418, 2014.

[11] Lozanovski, B. et al., Computational modelling of strut defects in SLM manufactured lattice structures. Mater. Des., 171, 2019.

[12] Ren, X., Shen, J., Tran, P., Ngo, T.D. \& Xie, Y.M., Design and characterisation of a tuneable 3D buckling-induced auxetic metamaterial. Mater. Des., 139, pp. 336-342, 2018.

[13] Ren, X., Shen, J., Tran, P., Ngo, T.D. \& Xie, Y.M., Auxetic nail: Design and experimental study. Compos. Struct., 184(Oct. 2017), pp. 288-298, 2018. 
[14] Yang, L., Harrysson, O., West, H. \& Cormier, D., Correction to: Modeling of uniaxial compression in a 3D periodic re-entrant lattice structure. J. Mater. Sci., 48(4), pp. 1413-1422, 2013. DOI: 10.1007/s10853-012-6892-2; J. Mater. Sci., 55(21), p. 9144, 2020.

[15] Mahmoudi, M., Elwany, A., Yadollahi, A., Thompson, S.M., Bian, L. \& Shamsaei, N., Mechanical properties and microstructural characterization of selective laser melted 17-4 PH stainless steel. Rapid Prototyp. J., 2017.

[16] Maconachie, T. et al., SLM lattice structures: Properties, performance, applications and challenges. Mater. Des., 183, 2019.

[17] Köhnen, P., Haase, C., Bültmann, J., Ziegler, S., Schleifenbaum, J.H. \& Bleck, W., Mechanical properties and deformation behavior of additively manufactured lattice structures of stainless steel. Mater. Des., 145, pp. 205-217, 2018.

[18] Concli, F., Gilioli, A. \& Nalli, F., Experimental - numerical assessment of ductile failure of additive manufacturing selective laser melting reticular structures made of Al A357. Proc. Inst. Mech. Eng. Part C: J. Mech. Eng. Sci., 32(7), pp. 3047-3056, Mar. 2019.

[19] Nalli, F., Cortese, L. \& Concli, F., Ductile damage assessment of Ti6Al4V, 17-4PH and AlSi10Mg for additive manufacturing. Eng. Fract. Mech., 241, 2021.

[20] Bonaiti, L., Concli, F., Gorla, C. \& Rosa, F., Bending fatigue behaviour of 17-4 PH gears produced via selective laser melting. Procedia Struct. Integr., 24, pp. 764-774, 2019.

[21] Concli, F. \& Gilioli, A., Numerical and experimental assessment of the static behavior of 3D printed reticular Al structures produced by selective laser melting: Progressive damage and failure. Procedia Struct. Integr., 12, pp. 204-212, 2018.

[22] Ramberg, W. \& Osgood, W.R., Description of Stress-Strain Curves by Three Parameters, Washington DC, 1943.

[23] Hollomon, J.R., Tensile deformation. Trans. AIME, 162, pp. 268-277, 1945.

[24] Maccioni, L., Rampazzo, E., Nalli, F., Borgianni, Y. \& Concli, F., Low-cycle-fatigue properties of a 17-4 $\mathrm{PH}$ stainless steel manufactured via selective laser melting. Material and Manufacturing Technology XI, vol. 877, pp. 55-60, 2021.

[25] Maccioni, L., Fraccaroli, L. \& Concli, F., High-cycle-fatigue characterization of an additive manufacturing 17-4 PH stainless steel. Key Engineering Materials, 2020.

[26] ASTM, Standard practice for statistical analysis of linear or linearized stress-life (s-n) and strain-life (e-n) fatigue data. E ASTM 739-91, 2006.

[27] Maccioni, L., Fraccaroli, L., Borgianni, Y. \& Concli, F., High-cycle-fatigue characterization of an additive manufacturing 17-4 PH stainless steel. 11th International Conference on Materials and Manufacturing Technologies, p. MT013, 2020.

[28] Alomar, Z. \& Concli, F., A review of the selective laser melting lattice structures and their numerical models. Adv. Eng. Mater., 22(12), 2020.

[29] www.code-aster.org.

[30] Concli, F. \& Gilioli, A., Numerical and experimental assessment of the mechanical properties of 3D printed 18-Ni300 steel trabecular structures produced by selective laser melting - A lean design approach. Virtual Phys. Prototyp., 2019.

[31] https://dakota.sandia.gov/. 